\title{
3D magnetic filed distribution in a screw double-stator induction motor
}

\author{
Nikolai Zablodskiy, Vladyslav Pliugin
}

\begin{abstract}
Ansys Maxwell calculation result of $3 \mathrm{D}$ magnetic field in doublestator screw induction motor with hollow outer ferromagnetic rotor is given.
\end{abstract}

Key words - magnetic field, distribution, induction motor, screw, ferromagnetic rotor.

\section{INTRODUCTION}

Creation of resource and energy saving technologies based on the integration of the functional properties of one unit and the using of dissipation energy. For the technological systems that integrate the processes of transportation, heating, mixing materials, the most perspective is resource conservation by combining individual units of equipment in the one body. This is providing using of the dissipation energy, which in traditional energy conversion scheme is useless dissipate into the environment. One of the main ways to improve the technical and economic performance of the electric drive is creation of motor-pumps, motor-mixers, motorscrews combined in one body [1]. This is a perspective class of electromechanical systems for the direct implementation of technological processes and differing of concentration enhanced functionality and energy properties [2].

The screw induction motor (SIM) design is shown on Fig. 1.

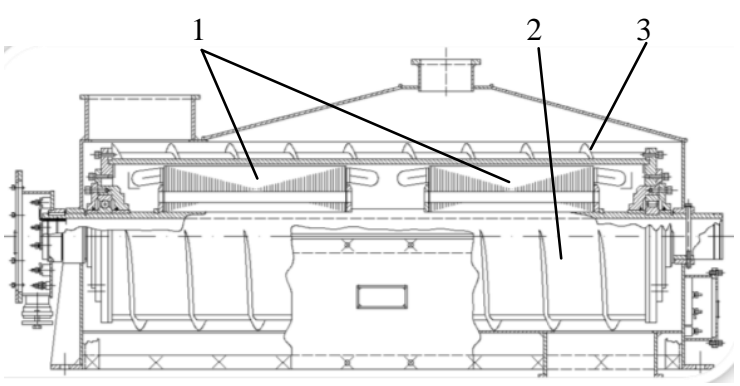

1 - stators; 2 -ferromagnetic rotor; 3 - screw

Fig. 1 - Screw induction motor

Screw induction motor consists of two stator modules that operate in opposition. Two stators stetted on a common hollow shaft creates opposite direction al electromagnetic torques, providing the required low rotation speed of the hollow ferromagnetic rotor cylinder without the using of mechanical gearbox [3]. A rotor having a screw that's allows, beside the material transportation, simultaneously heats it during moving along the rotor body throw the screw.

Total SIM efficiency is very high, which provides the effective implementation of the energy saving principles. The SIM using a hollow ferromagnetic rotor construction, which simultaneously performs the functions of the rotor, the heater, the screw actuator and the container body. The outer rotor surface is cooled by a raw materials which, in turn, heats up, providing evaporation of moisture from it.

Significant advantages of using SIM technology is not only the high value of efficiency, but also a significant reduction in the production area, the quantity of equipment units for the same technological operations and its payback period.

In this regard, an important scientific and practical problem is the creation SIM to perform new specific functions for technological applications, including plastics hot-pressing and technical air conditioning in electric machines, heat-generating systems.

\section{SIMULATION AND RESEARCH RESULTS}

This paper presents the results of simulation of 3D electromagnetic field distribution in the SIM with the mutual work of the two stator units, operating in opposition.

The calculation model is based on the real factory made SIM prototype with the rated power $55 \mathrm{~kW}$ of driving module and $45 \mathrm{~kW}$ of braking module.

The task of electromagnetic field distribution for mutual work of two electromechanical devices in one project is solved for the first time. The problem was solved in program Ansys Maxwell together with colleagues from the Czech Technical University, who provided the licensed distributed server station for calculations.

The stator winding is created using the Ansys Maxwell graphics library that's allow to take into account as well the winding active zone as its frontal part. To reduce the simulation time $1 / 8$ of the machine centerline symmetry, and $1 / 2$ - by axial symmetry has been taken (Fig. 2).

In addition, two SIM modules works on the common electrical shaft - external hollow ferromagnetic rotor, that's complicates the task of simulation. The main difficulty consists in applying of coils excitation signals in such way that they are perceived by the program as independent objects with separate power supply. 


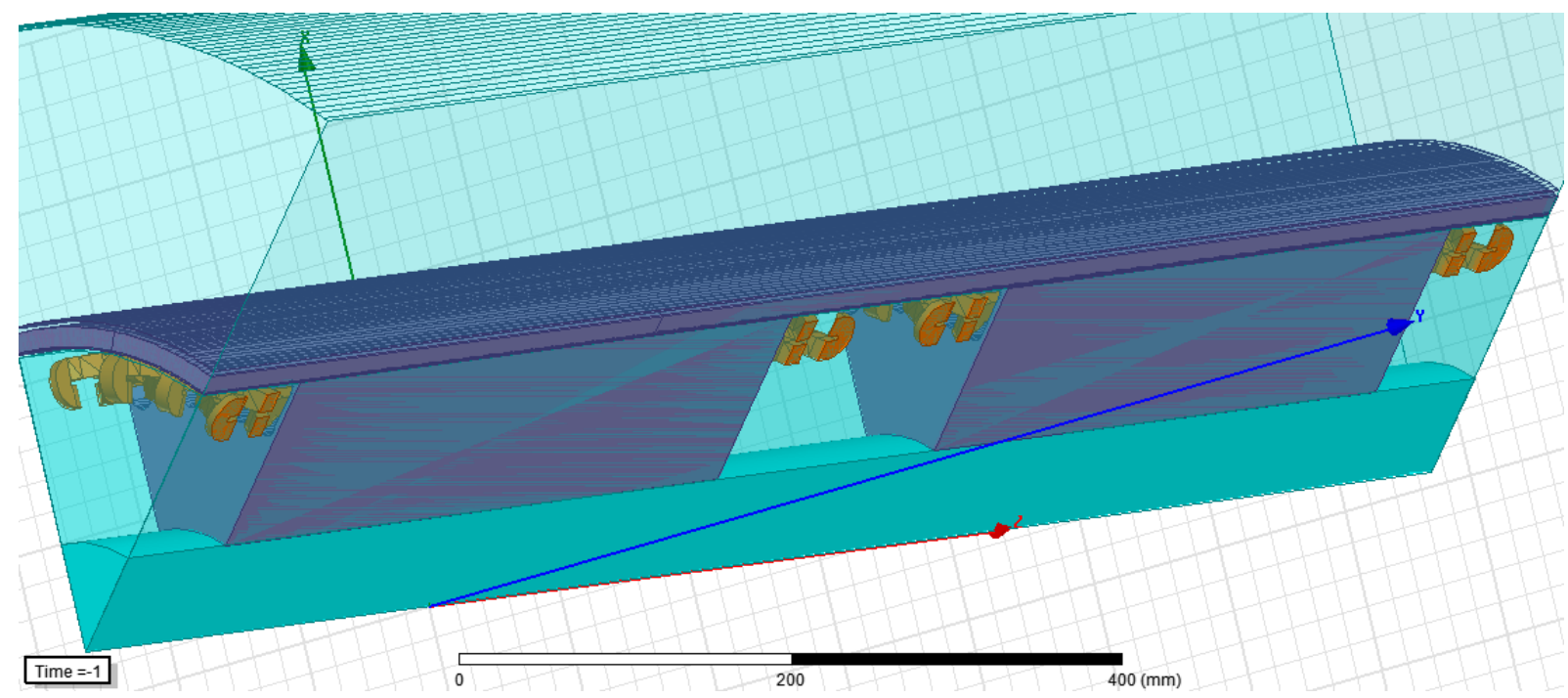

Fig. 2 - 3D model of the SIM in Ansys Maxwell project design

To solve the problem the phase of each module has been supplied by external circuit terminals, created in Maxwell Circuit Editor (Fig. 3).

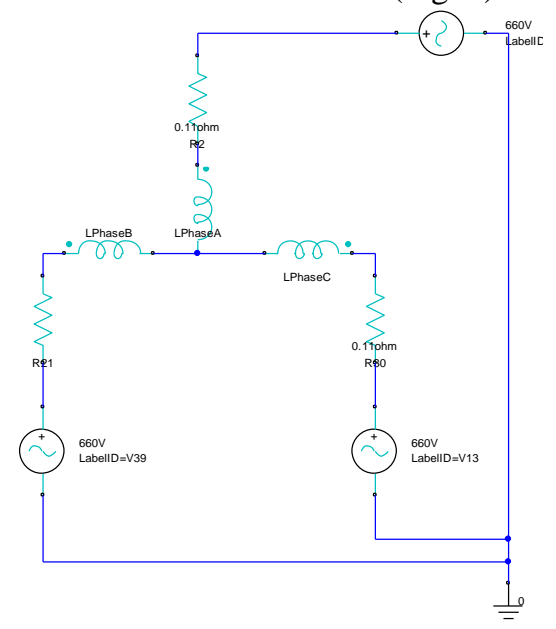

Fig. 3 - SIM supply circuit

The electromagnetic field distribution is shown on Fig. 4.

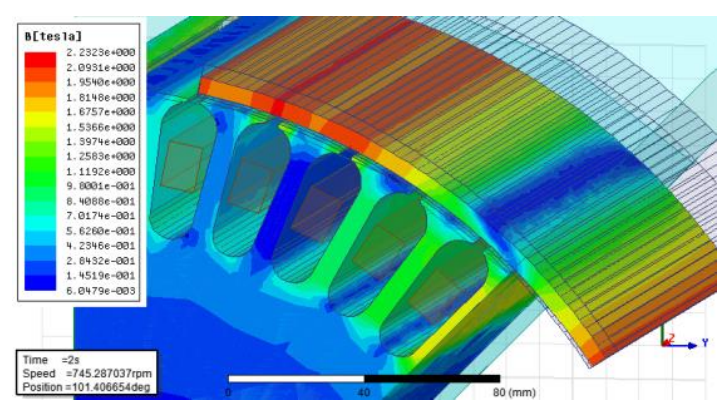

Fig. 4 - Distribution of induction magnitude in SIM

Changing of the SIM driving module speed at non-load start is shown on Fig. 5. As we can see, the rotor comes to synchronous speed and will continue to rotate without noticeable vibrations near the point of dynamic equilibrium.

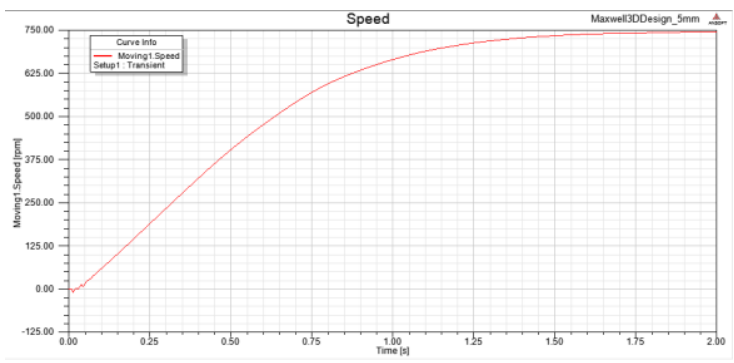

Fig. 5 - Moving speed chart of the SIM driving module

Current chart is shown on Fig. 6 and torque chart is show on Fig. 7.

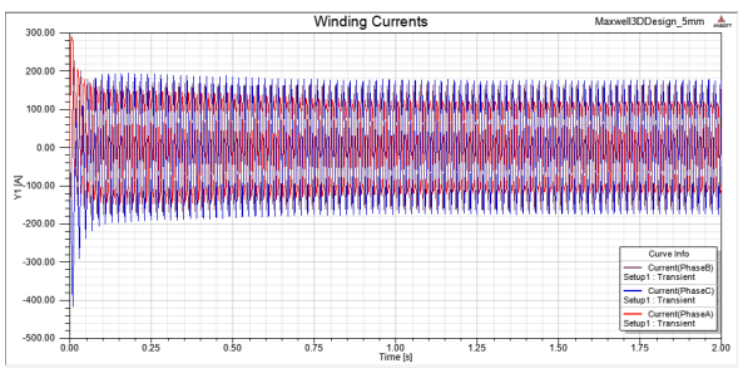

Fig. 6 - Starting currents of the SIM

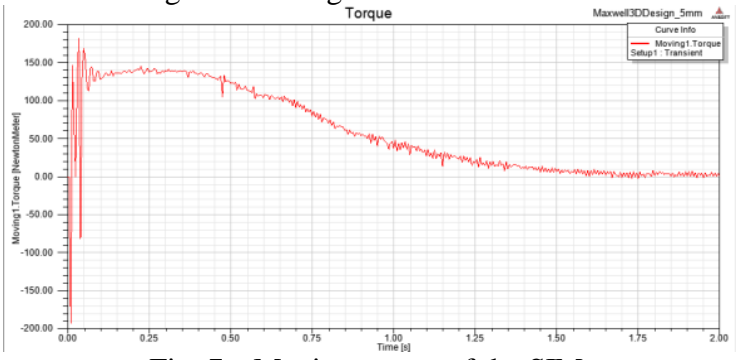

Fig. 7 - Moving torque of the SIM

Vector of electromagnetic field tension distribution is show on Fig. 8. 


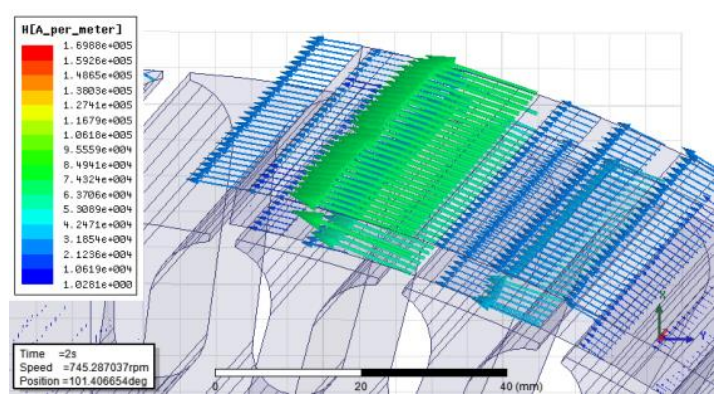

Fig. 8 - Distribution of the electromagnetic filed vector in SIM

The results of calculations are confirmed by comparison with the diagram of SIM losses distribution obtained in experimental research (Fig. 9).

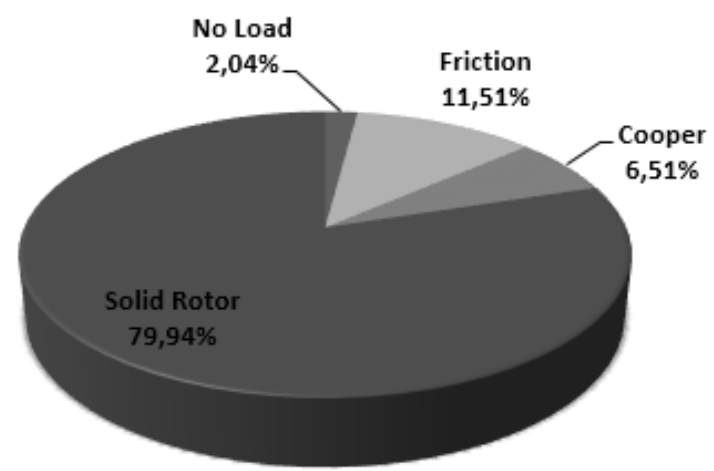

A

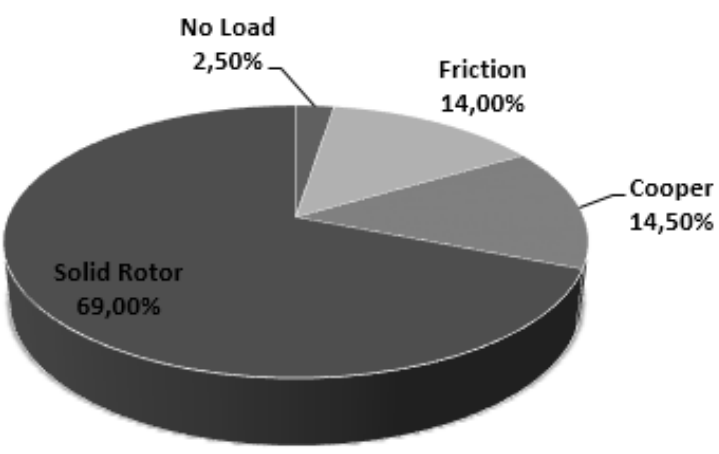

B

\begin{abstract}
A) calculation
B) experiment
\end{abstract}

Fig. 9 - Losses diagrams of the SIM

The calculated losses in SIM rotor and losses in the stator winding on diagram (Fig. 9) has some differ from the results of experimental studies. This discrepancy is explained by the fact that the value of losses in the rotor during the experiment was determined indirectly by the difference in temperature of the ferromagnetic rotor before and after the experiment. As a result, the percentage loss of redistributed, and as a result less, compared with the expectation value of losses in the rotor gave a larger percentage weight loss in the stator winding. The discrepancy between the measured and calculated values of the absolute value does not exceed $18 \%$.

It should be noted that the results obtained for the three-dimensional model has a small divergence of the results obtained in two-dimensions, but differ slightly in their numerical values. Meanwhile, the three-dimensional model allows access to the parameters that are not available when the twodimensional model.

In particular, it concerns the determination of the resultant torque of two oppositely working modules. The objective of the integrated solutions in a one 3D-space of driving and braking models takes twice time in compare with solution for a single module, but it allows to perform the actual physical simulation of a double-stator system as close as possible to a real SIM prototype.

\section{CONCLUSION}

The results can be used to optimize the SIM design, in physical simulation of machine before its practical manufacturing, improving the quality calculation methods.

The research field model of SIM with a ferromagnetic rotor in Ansys Maxwell was solved. The analysis for solving problems of the electromagnetic field distribution in 3D performances was held.

A 3D simulation of a double-stator system in which the driving and braking modules are modeled together in one project space with the separate external power supply and tight connection of the stators with common ferromagnetic rotor was implemented.

\section{REFERENCES}

[1] N.N. Zablodsky, V.E. Plyugin, M.A. Filatov, V.A. Kvasov, and H.M. Grin "Object-oriented designing electro-thermo-mechanical converters with optimum thermodynamic structure", Dunaujvarosi Foiskola Közlemenyei XXIX, vol. 1, 2007, pp. $193-200$.

[2] N. Zablodskiy, V. Pliugin, and V. Gritsyuk "Submersible electromechanical transformers for energy efficient technologies of oil extraction", Progressive technologies of coal, coaled methane, and ores mining, Leiden, 2014, pp. $223-227$.

[3] N. Zablodskij, V. Pliugin, J. Lettl, and S. Fligl "Dynamic Simulation of the Double-Stator Induction Electromechanical Converter with Ferromagnetic Rotor", Power Engineering, Istanbul, 2013, pp. 1448 - 1453. 


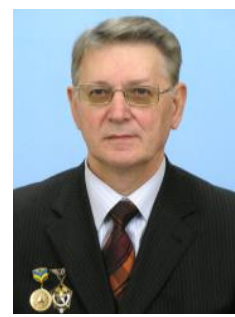

Nikolai Zablodskiy

DSc., prof.,

The head of a chair "Electrical machines and apparatus", first vice rector of Donbas state technical university, Lysychansk, Ukraine.

E-mail: zablodskiynn@gmail.com

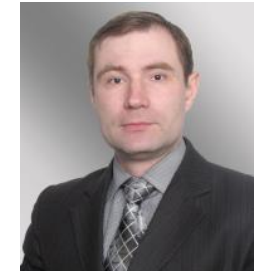

Vladyslav Pliugin

CSc., doc.,

chair "Electrical machines", National technical university "Kharkiv polytechnic institute", Ukraine.

E-mail: vlad.plyugin@gmail.com 